\title{
HORTA VIVA: A PRODUÇÃO DE HORTALIÇAS ORGÂNICAS NO AMBIENTE ESCOLAR COMO FERRAMENTA DE ENSINO NA EDUCAÇÃO AMBIENTAL E ALIMENTAR
}

\author{
Leonardo da Silva Santos ${ }^{1}$ \\ Roberto Santos Rocha ${ }^{2}$ \\ Jadielma Paulino dos Santos ${ }^{3}$ \\ Lyslem Riquelem de Araújo ${ }^{4}$ \\ Millena Duarte Costa ${ }^{5}$ \\ Maria Darleide Pinheiro da Silva ${ }^{6}$ \\ Claudimary Bispo dos Santos ${ }^{7}$
}

Resumo: A horta é uma ferramenta de ensino e aprendizagem de grande importância nas escolas, principalmente por possibilitar vários tópicos em um "laboratório vivo" que, ao final de cada ciclo, servirá de alimento para a própria comunidade escolar. Assim, o presente trabalho teve como objetivo promover a Educação Ambiental e alimentar através da implantação de uma horta escolar de base agroecológica em uma escola de Ensino Fundamental de Arapiraca, AL. Para isso, foram realizados oficinas e minicursos sobre temas que contextualizassem as temáticas abordadas, para que, em seguida, fosse dado início ao processo de implantação da horta e cultivo das hortaliças.

Palavras-chave: Agroecologia; Meio Ambiente; Ensino; Aprendizagem; Ciências.

\footnotetext{
${ }^{1}$ Universidade Estadual de Alagoas. E-mail: leossanto.bio@gmail.com.

2 Universidade Estadual de Alagoas. E-mail: roberto_bio@outlook.com.

3 Universidade Estadual de Alagoas. E-mail: jadysantos3@gmail.com.

${ }^{4}$ Universidade Estadual de Alagoas. E-mail: araujolyslem23@gmail.com.

5 Universidade Estadual de Alagoas. E-mail: millenad414@gmail.com.

6 Universidade Estadual de Alagoas. E-mail: maria.silva33@alunos.uneal.edu.br.

${ }^{7}$ Universidade Estadual de Alagoas. E-mail: claudimarybs@hotmail.com.
} 
Abstract: The vegetable garden becomes an important teaching and learning tool in schools, mainly because it makes possible to approach several topics in a "living laboratory" which, in the end of each cycle, will serve as food for the school community itself. Thus, the present work aimed to promote environmental and food education through the implementation of an agroecological school garden in an elementary school in Arapiraca, AL. For this, workshops and short courses were held on themes which contextualize the themes addressed, so that, afterwards, the process of establishing the vegetable garden and growing vegetables could be started.

Keywords: Agroecology; Environment; Teaching; Learning; Sciences.

\section{Introdução}

Os impactos ambientais gerados pela ação humana já eram sentidos no meio ambiente bem antes do processo da revolução industrial, mas foi depois desse processo de industrialização que vários países passaram a fazer o uso descontrolado dos recursos naturais, causando impactos de formas mais intensas e alarmantes, jamais vistos. Nas últimas décadas, as pautas ambientais vêm sendo bastante discutidas, tais como: clima, aquecimento global, utilização demasiada de agrotóxicos na agricultura e demais alterações causadas no planeta pela agressão ao meio ambiente causada pelo homem (BARBIERI, 2016).

Assim, a Educação Ambiental (EA) surge como uma abordagem direcionada para as questões ambientais não resolvidas, com o principal objetivo de, através do enfoque interdisciplinar e da articulação entre dimensões social e ambiental, inserir aos cidadãos conhecimentos, valores e responsabilidades em torno de questões ambientais. (MEDEIROS et al., 2011).

A falta de conhecimento dos alunos sobre as questões ambientais e de ações desenvolvidas com relação à Educação Ambiental, sustentabilidade e Educação Alimentar são constatados nas escolas (PANTOJA, 2013). Dessa maneira, despertar a consciência ambiental e implementar hábitos de vida saudáveis e ecológicos devem estar entre as preocupações principais das escolas, para que assim seja possível formar adultos mais conscientes e preocupados com esses aspectos.

Buscando promover o conhecimento, e com intuito de solucionar esses problemas, podem ser construídas hortas escolares, cujo espaço seja utilizado para estimular hábitos de alimentação saudáveis e proporcionar vivências ímpares no aprendizado e na vida dos indivíduos. Segundo Morgado (2008), través da horta é possível contextualizar teoria e prática, o que traz benefícios importantes para a formação educacional dos discentes, além de proporcionar uma excelente ferramenta para o ensino e a construção de opiniões críticas que estimulam a aprendizagem e a socialização, tanto dos alunos entre si, quanto destes com os demais agentes educacionais. 
Além disso, Morgado (2008) ainda enfatiza que a horta altera sensivelmente a relação das pessoas com os ambientes naturais e urbanos, pois estimula a construção dos princípios de sustentabilidade e a valorização dos recursos naturais. Assim, a horta torna-se uma ferramenta de ensino e aprendizagem de grande importância em escolas, principalmente por possibilitar abordar vários tópicos em um "laboratório vivo" que, ao final de cada ciclo, servirá de alimento para a própria comunidade escolar (ANSCHAU et al., 2018).

\section{Educação Ambiental}

No princípio da raça humana, existia uma singularidade entre homem e a natureza, o andamento e velocidade de suas vidas estavam totalmente conectados. Isso se desfez a partir do momento em que o ser humano deixou de utilizar a natureza para sua subsistência e passou a explorar a matériaprima retirada do meio ambiente para fins de produção, passando a ser favorecido financeiramente (OLIVEIRA; SILVA, 2020, p.87). A cada dia a ganância do homem aumenta e, por isso, é necessária a interferência da Educação Ambiental para que tal fato não seja inalterável.

Buscando modificar essas formas de portar-se dos seres humanos, dispõe a carência de questionar o modelo de desenvolvimento social atualmente empregado, tal como suas consequências ao meio natural. Por meios de programas, leis, acordos internacionais e outros, procura-se comover a sociedade em meio a importância da proteção do meio ambiente (MENDES; LOPES; SALLES, 2014, p.16).

Nessa situação, é de grande necessidade a abordagem da Educação Ambiental nas escolas, podendo trazer questionamentos para a educação e transformando-a, levando elementos e metodologias eficazes (OLIVEIRA; SILVA, 2020, p.87).

\section{Educação Ambiental no Brasil}

A Educação Ambiental tornou-se exigência no Brasil a partir da publicação da Constituição Federal em 1988, quando instituída a Política Nacional do Meio Ambiente, tal como o Sistema Nacional do Meio Ambiente pela Lei $n{ }^{\circ} 6.938 / 81$ e foi assegurado pelos governos federal, estadual e municipal (BRASIL, 2008).

Através da Lei n.ำ 9795/99 da Política Nacional de Educação Ambiental aprovada em 1999, entende-se que

os processos pelos quais tanto o indivíduo quanto a coletividade "constroem valores sociais, conhecimentos, habilidades, atitudes e competências voltadas para a conservação do meio ambiente, bem de uso comum do povo, essencial a sadia qualidade de vida e sua sustentabilidade (BRASIL, 1999). 
A Educação Ambiental ultrapassa diversas áreas do conhecimento, mantendo uma complexidade ambiental (LEFF, 2001). De acordo com a UNESCO (2005), a EA é definitivamente uma disciplina que destaca a ligação entre homem e meio ambiente, expondo as formas de conservação, de administração dos recursos naturais e suas formas de prevenção.

\section{Educação Ambiental nas escolas}

A escola é um ambiente primordial para o desenvolvimento do entendimento social e coletivo, e trazer a Educação Ambiental para este meio, é essencial, de modo a contribuir com novos comportamentos e em atitudes já praticadas pelos estudantes, conseguindo resultados de valorização com o meio ambiente.

Através da Política Nacional de Educação Ambiental instituída pela Lei 9.795/1999, na qual visa a educação ambiental no âmbito escolar, impõe que "a Educação Ambiental será desenvolvida como uma prática educativa integrada, contínua e permanente em todos os níveis e modalidades do ensino formal' (BRASIL, 1999).

É notório que a Educação Ambiental venha agregar grande aprendizado para os alunos, podendo formar não só bons alunos, mas, pessoas conscientes. Porém, para que esse desenvolvimento seja positivo, é necessária uma boa execução, as escolas podem aplicar ações práticas, fugindo um pouco da teoria e fazendo com que o aluno conheça e desenvolva ações para conservar o meio ambiente (MEDEIROS et al., 2011: p. 2).

A educação, seja ela de qualquer modo desenvolvido, pode alcançar uma grande mudança na vida e no futuro das pessoas, podendo rever atitudes e transformando práticas sociais, baseando-se numa compreensão apropriada do meio ambiente, tanto do planeta, como principalmente do ambiente local, sendo capaz de construir uma sociedade mais correta e sustentável que, de qualquer modo, se torna uma forma excelente para que se obtenha êxito no seguimento sustentável (DIDONET, 2015, p.6).

\section{Educação alimentar no Brasil}

Ao se tratar da educação alimentar e nutricional há uma enorme importância para que as pessoas vivam melhor. Nesse sentido, com o passar do tempo, esse assunto tem crescido para que a partir de diversas tentativas e erros houvesse um aperfeiçoamento no desenvolvimento da área (SANTOS, 2012). Dessa maneira, diz-se que a fundamentação de conceitos sobre as práticas alimentares têm sido um movimento adotado politicamente, também como uma forma estratégica voltada para a alimentação e nutrição, e não somente em sua teoria, como também no dinamismo de ações, no incentivo de práticas saudáveis quanto a ingestão de alimentos (SANTOS, 2005). 
O interesse da educação nutricional pelos brasileiros teve início em 1940, quando houve uma preocupação governamental das condições alimentares da classe trabalhadora (BOOG, 1999). Com o passar do tempo, entre 1950 a 1960, houve a possibilidade da colocação da soja nos pratos brasileiros através de campanha concernente a Educação Nutricional (BOOG, 1997). Em resumo, entre as décadas de 40 a 70 compreendeu-se que todos deveriam contribuir na busca de melhorias na educação nutricional (CERVATO-MANCUSO et al., 2016).

No ano de 1996 foi sancionado pelo presidente Michel Temer a Lei oㅡ 9.394, de 20 de dezembro do ano citado anteriormente, contida na Lei de Diretrizes e Bases da Educação Nacional, com alteração para a Lei $n^{\circ} 13.666$ de maio de 2018 onde a educação alimentar e nutricional foi incluída no currículo escolar (ARAÚJO et al., 2019).

Apesar da existência de diversos programas governamentais no Brasil com o foco em práticas alimentares saudáveis, ainda assim existe uma lacuna a ser preenchido nesse requisito, aliás:

As ações estruturantes de Educação Alimentar e Nutricional desempenham uma função estratégica para a promoção da segurança alimentar e nutricional em todas as suas dimensões, passando desde a produção até o consumo dos alimentos, considerando aspectos éticos, culturais, socioeconômicos e regionais, entre outros, na promoção de hábitos alimentares adequados e saudáveis (OLIVEIRA; OLIVEIRA, 2008, p. 496).

Nessa feita, são diversas mudanças com o passar do tempo e essas variações sempre buscam melhorar a situação alimentar no país, que outrora se voltava na distribuição de alimentos e na promoção do conhecimento sobre o assunto atualmente, na mudança individual de cada pessoa em sua particularidade, sem esquecer dos saberes científicos, havendo a interação de todos que vai do individual até chegar em sua coletividade (CERVATOMANCUSO et al., 2016).

\section{Educação alimentar na escola}

$\mathrm{O}$ ato e as escolhas alimentares vão caracterizando a identidade de grupos e estratos sociais, como reflexos da distribuição econômica e da relação de pertencimento e reconhecimento, permeados por disparidades, regras, costumes, tradições e representações coletivas e simbolismos (CANESQUI; GARCIA, 2005) e modelam o comportamento alimentar das diferentes culturas. As preferências alimentares de cada um são forjadas desde a infância pelas sensações que são apresentadas e vivenciadas pela criança, através do tato, sabor e odor (CANESQUI; GARCIA, 2005), de suas 
consequências orgânicas e do contexto ambiental, familiar e social nos quais ocorrem essas experiências (RAMOS; STEIN, 2000).

O processo de industrialização, característico das últimas décadas, trouxe alimentos estranhos e adulterados. Para Cascudo (2004), um dos grandes fatores negativos é a decadência nacional da refeição doméstica, ou seja, o abandono dos pratos tradicionais. Diante desse cenário, a abordagem sobre educação alimentar deve ser pensada para além do aspecto nutricional, considerando, no seu planejamento, os diferentes eixos que compõem o referido tema, visando desenvolver nos alunos o pensamento crítico e a conscientização sobre sua cultura e o modo de fazer suas escolhas alimentares (PIPITONE et al., 2003). Portanto, posiciona-se a educação alimentar em uma perspectiva multidisciplinar, com elos entre diversas áreas de saber (LIMA, 2008).

$\mathrm{Na}$ educação formal, o ambiente escolar destaca-se como local adequado e propício para a implementação da Educação Alimentar e Nutricional (EAN), pois é nele que as práticas pedagógicas necessárias para o processo de aprendizagem e melhoria da qualidade de vida ocorrem (BIZZO; LEDER, 2005). Vale lembrar que a escola tem sido um dos espaços mais focados pelas políticas públicas de alimentação e nutrição com a promoção da alimentação saudável, reconhecida como o lócus prioritário de formação de hábitos e escolhas (SANTOS, 2012).

Nesse contexto, ter a inserção de uma horta no ambiente escolar irá permitir, além de aulas práticas mais dinâmicas no ensino de Ciências, a formação de cidadãos conscientes e atentos aos impactos ambientais, com um olhar mais responsável aos recursos naturais e de um manejo agrícola mais sustentável, reconhecendo a importância do meio ambiente, ecossistemas e relações ecológicas que dependem de um equilíbrio dinâmico, bem como na construção de uma noção de hábitos alimentares e nutricionais mais saudáveis. Assim, o presente trabalho teve como principal objetivo promover a Educação Ambiental e alimentar, através da implantação do projeto de extensão Horta Viva, em que foi implantada uma horta escolar de base agroecológica em uma escola de Ensino Fundamental do município de Arapiraca-AL.

\section{Local de implantação do projeto Horta Viva}

O projeto foi realizado na Escola Municipal de Educação Básica Governador Divaldo Suruagy, situada no município de Arapiraca, Estado de Alagoas, durante o período de janeiro a junho de 2019, desenvolvido pelos acadêmicos do Curso de Licenciatura em Ciências Biológicas da Universidade Estadual de Alagoas (UNEAL), bolsistas do subprojeto de biologia do Programa Institucional de Bolsas de Iniciação à Docência (PIBID), sob a supervisão da Professora de Ciências. O público-alvo foram os alunos de duas turmas de oitavo ano e duas turmas de nono ano, envolvendo cerca de 120 alunos do 
Ensino Fundamental II. No ano em que o projeto foi realizado, a escola atendia cerca de 528 alunos matriculados no turno matutino.

O município de Arapiraca pertence à Mesorregião do Agreste Alagoano, localiza-se a oeste da capital do Estado, distando desta cerca de $128 \mathrm{~km}$. Possui uma população estimada de 231.747 habitantes, ou seja, o segundo mais populoso do Estado de Alagoas e o primeiro de sua microrregião. Sua área é de $345,655 \mathrm{~km}^{2}$, sendo que $8,6874 \mathrm{~km}^{2}$ estão em perímetro urbano (IBGE, 2019). Em relação aos dados educacionais, Arapiraca possui 115 Escolas de Ensino Básico (Educação Infantil, Ensino Fundamental e Ensino Médio); dez (10) Escolas Municipais de Tempo Integral; três (03) Centros de Ensino Superior e duas Universidades Públicas e outras Instituições de Ensino Superior, que trabalham com a Educação Superior Presencial e a Distância.

\section{Processo de implantação do projeto Horta Viva}

De início, foi necessário planejar estratégias para adquirir confiança da comunidade escolar, uma vez que, não acreditavam que fosse possível obter êxito, pois, anteriormente, havia ocorrido uma tentativa de implantação de um projeto semelhante, o qual não obteve sucesso. A falta de êxito na execução do projeto anterior, entre outros motivos, ocorreu devido pobreza de nutrientes do solo do local da implantação, sendo até reprovado por um profissional da área agrícola do município, além da presença de erva daninha, muito comum na região, conhecida pelo nome de capim alho (Figura 1).

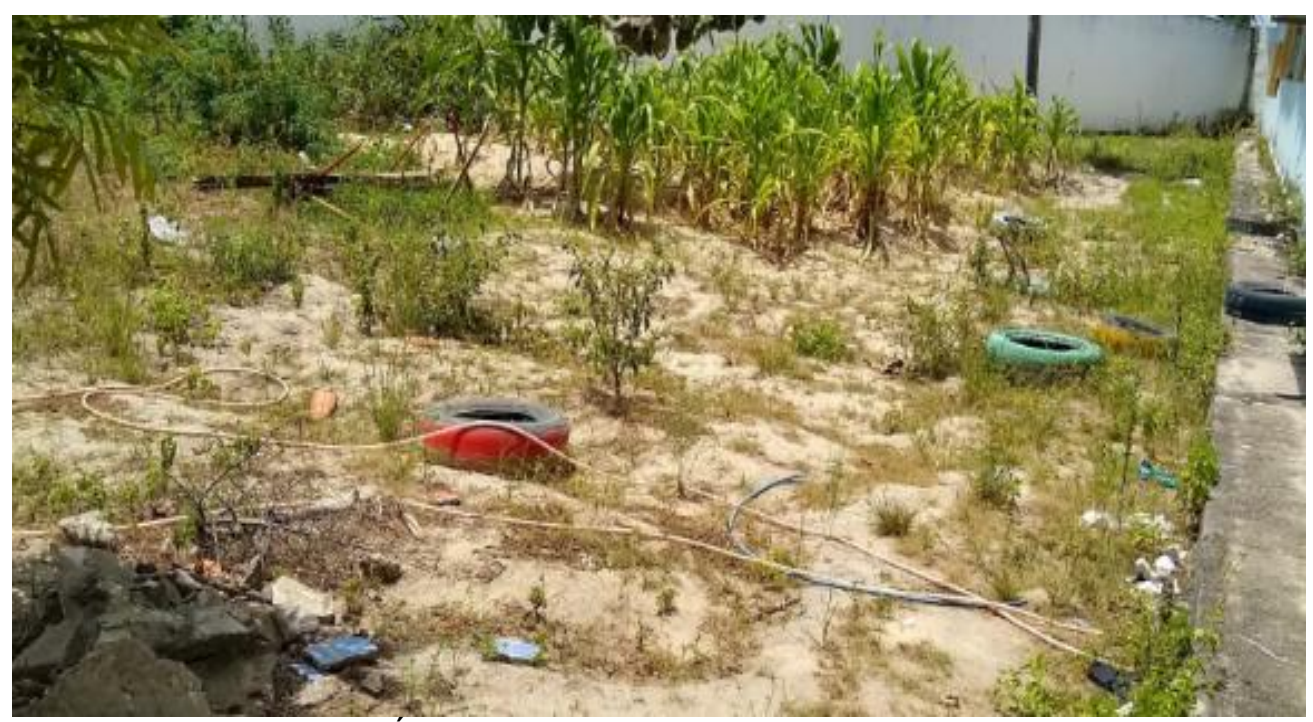

Figura 1: Área projetada para implantação da horta escolar.

Fonte: Acervo dos autores (2019). 


\section{Implantação da horta escolar}

A partir da exposição do tema "a importância de uma horta no ambiente escolar" abordado para as turmas envolvidas, surgiram sugestões de como poderiam revitalizar a mesma área, utilizada anteriormente, cujo espaço físico era o mais adequado.

Dessa forma, o primeiro passo foi o reconhecimento do local e a limpeza dele, ocorrendo então a retirada das metralhas existentes no entorno. Além disso, com a participação da comunidade escolar e dos acadêmicos pibidianos, foi realizada a eliminação da erva daninha presente em todo o espaço (Figura 2). Nessa área foram demarcados e confeccionados 12 canteiros, sendo seis (06) com dimensões de $3,0 \mathrm{~m}$ de comprimento por $0,80 \mathrm{~cm}$ de largura e seis (06) canteiros com dimensões de 8,0 m de comprimento por 0,85 cm de largura (Figura 3). Foram utilizados os materiais: enxada, enxadão, ciscador, pá, carro de mão, mangueira, regado, calcário dolomítico para a correção da acidez do solo, esterco bovino e compostagem - restos de matéria orgânica oriundos das árvores e da cozinha. Para o plantio foram usadas mudas das hortaliças (alface, coentro, couve, beterraba, cebola branca, cebolinha, pimentão, tomate e repolho) e sementes de coentro.

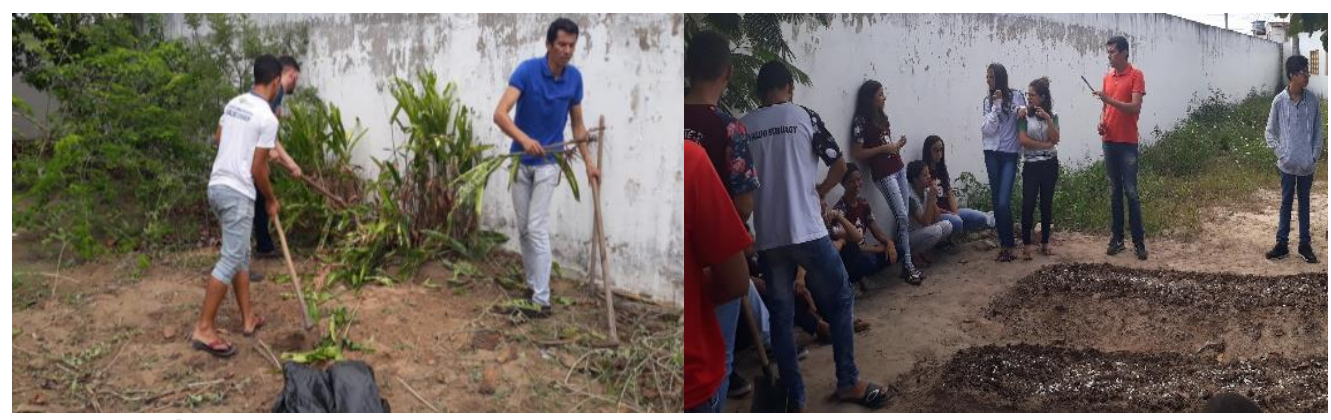

Figuras 2 e 3: Limpeza do local e demarcação dos canteiros.

Fonte: Acervo dos autores (2019).

A tarefa de preparação do solo foi a mais trabalhosa e demorada, por ser um terreno arenoso. Como o capim-alho é uma erva daninha, agressiva e de difícil controle, foi necessário fazer uma escavação onde todo o rizoma precisou ser retirado. Em alguns lugares, a profundidade chegou a pouco mais de $30 \mathrm{~cm}$. Nessa etapa de remoção, os alunos aprenderam a diferença entre erva daninha e plantas espontâneas, além de como fazer o controle delas em um plantio de hortaliças.

Outras etapas importantes aconteceram quando os alunos conheceram e aprenderam a técnica de correção de solo, utilizando adubação inorgânica calcário dolomítico, e a adubação orgânica - através do uso do esterco bovino e compostagem. Ressalta-se que houve um intervalo de tempo entre as duas adubações, a fim de que primeiro houvesse a redução da acidez do solo, através da calagem. 
Terminada a fase de preparação/calagem do solo e demarcação dos canteiros, foi realizado um minicurso de confecção de canteiros e vasos com garrafas pet e pneus (Figuras 4 e 5), para assim ser iniciada a fase de adubação com esterco bovino e outros nutrientes oriundos de matéria orgânica. A parir de então, foi iniciado o período de plantio e cuidados com a horta (Figuras 6 e 7 ).

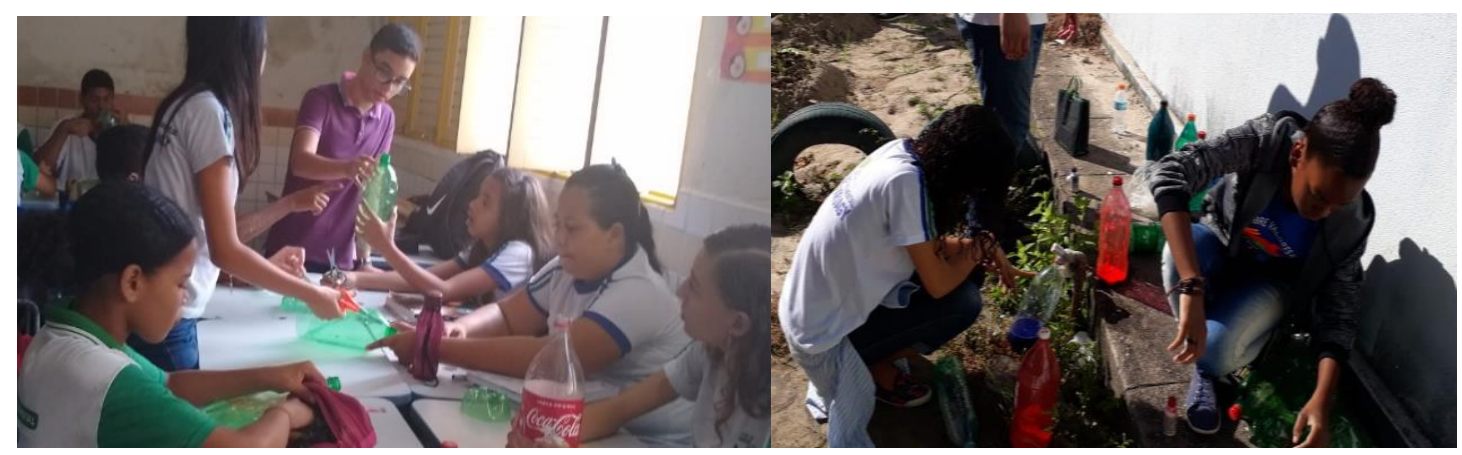

Figuras 4 e 5: Minicurso: confecção de canteiros e vasos com garrafas e pneus.

Fonte: Acervo dos autores (2019).

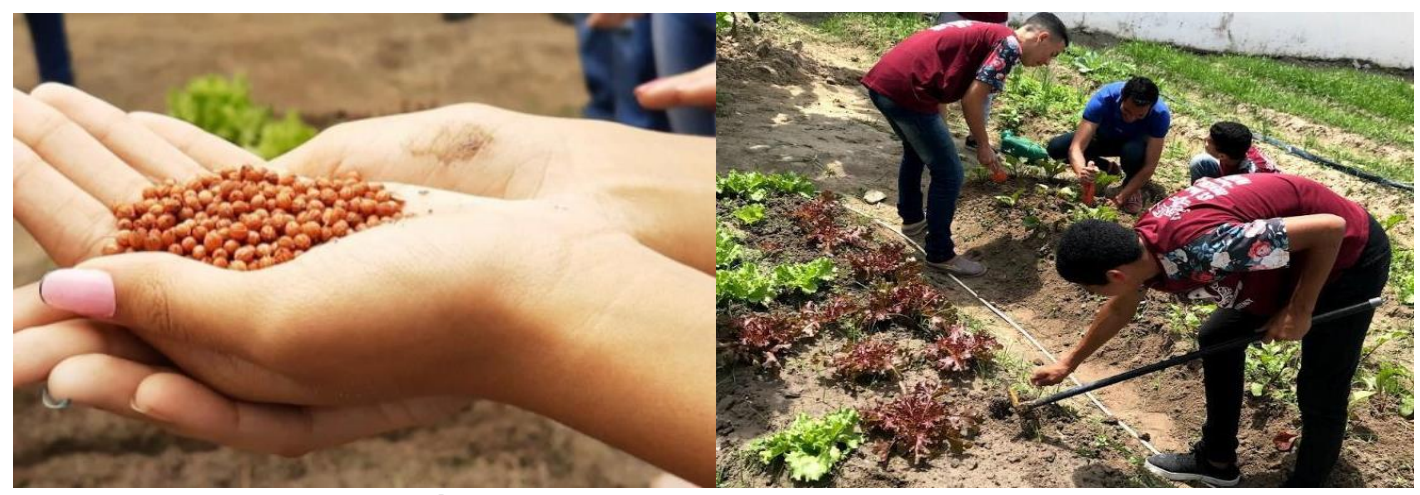

Figuras 6 e 7: Plantio e cuidados com a horta.

Fonte: Acervo dos autores (2019).

\section{Resultados e discussões}

Durante todas as etapas metodológicas desenvolvidas para a implantação da horta, na Escola Municipal de Educação Básica Divaldo Suruagy (EMEBDS), foi percebido o engajamento dos alunos, e o despertar do interesse pelos temas relacionados a ecologia e a saúde alimentar, no contexto da Educação Ambiental e educação em saúde (Figuras 8 e 9). Nesse sentido, acredita-se que abordagens pedagógicas interligadas à teoria com a prática podem formar cidadãos mais sensibilizados e conscientes em relação às questões ambientais e nutricionais. 


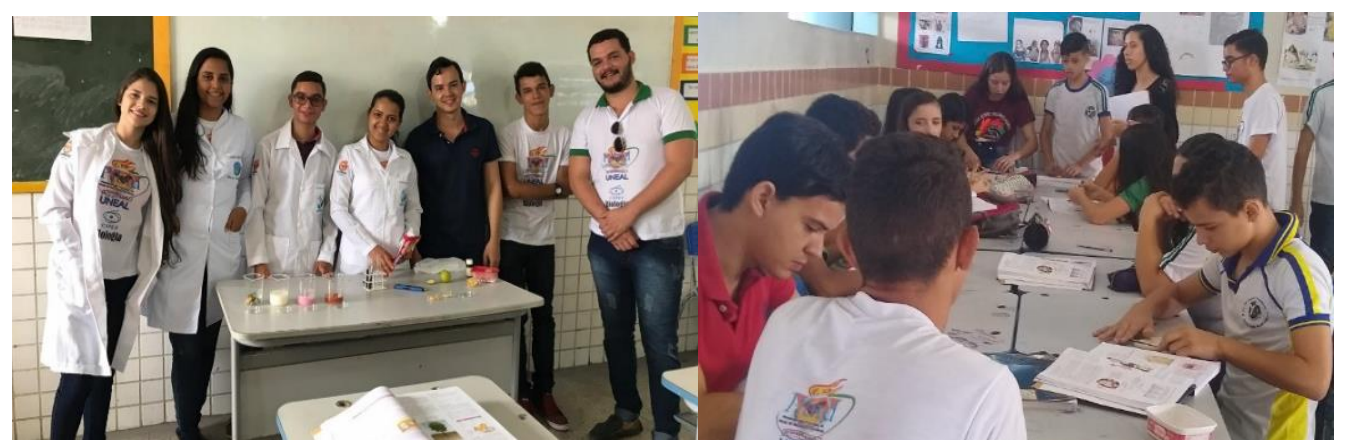

Figuras 8 e 9: Estudo ecológico e nutricional interligado a implantação da horta escolar.

Fonte: Acervo dos autores (2019).

O uso da horta escolar como ferramenta pedagógica na relação ensinoaprendizado é eficaz, tanto para a apreensão do conteúdo ministrado, bem como para a socialização entre os educandos envolvidos. Além disso, permitem incrementar a relação entre a conservação do solo, produção de alimentos, qualidade do solo (nutrientes, umidade, ausência de predadores naturais etc.), o que os torna mais responsáveis pela conservação ambiental (OLIVEIRA et al., 2018).

No presente estudo, foi também possível observar que as aulas se tornaram mais interativas e dinâmicas, sendo possível comparar a implantação da horta a um laboratório vivo. Ao realizarem um projeto semelhante, Anschau e colaboradores (2018) enfatizam que a horta proporcionou aos participantes uma nova ideia de alimentação saudável e de sustentabilidade em pequenos espaços, transformando um espaço ocioso da escola em um "laboratório vivo".

As hortaliças orgânicas cultivadas, tais como: alface, coentro, couve, beterraba, cebola branca, cebolinha, pimentão, tomate e repolho foram colhidas pelos alunos e professores, sendo disponibilizadas para a merenda escolar e também levadas para casa, beneficiando não somente os escolares, mas também os seus familiares (Figuras 10 e 11).

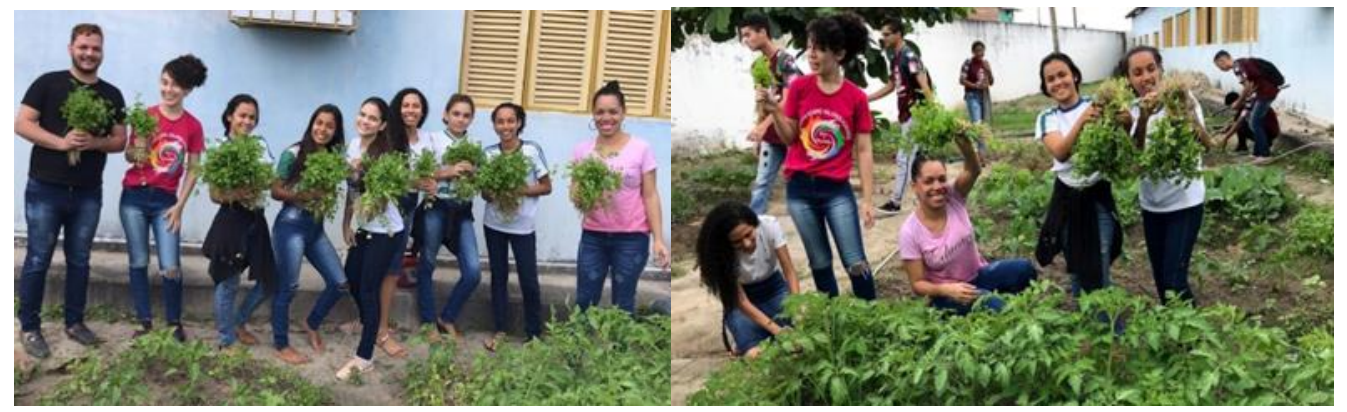

Figuras 10 e 11: Colheita das hortaliças cultivadas.

Fonte: Acervo dos autores (2019). 
melhorar o desempenho dos educandos nas tarefas escolares e elevar a visão acerca da sensibilidade ambiental, bem como na melhoria nos hábitos alimentares (FERREIRA et al., 2014).

Irala e Fernandez (2001) acreditam que a Educação Ambiental e a implantação de horta em escolas é, atualmente, um dos mecanismos de suma importância para se reverter, em diversos aspectos, o processo de degradação do meio ambiente, da redução da produção pouco sustentável na agricultura, além de permitir a formação de cidadãos mais críticos e com hábitos alimentares mais saudáveis.

Não obstante aos resultados expostos e de forma semelhante com a visão de outros estudos, como o de Dobbert et al., (2011), a horta escolar na EMEBDS permitiu um espaço de observação, pesquisa, ensino e extensão, onde técnicas mais ativas de aprendizagem foram utilizadas para trabalhar temas como cadeia alimentar, ciclos da matéria, decomposição, fotossíntese, equilíbrio e sustentabilidade ambiental e manutenção de ecossistemas produtivos, uso e conservação do solo, entre outros diversos temas. Além disso, assim como no trabalho realizado por Guenther e colaboradores (2020), a horta é mantida por um funcionário da escola e os alunos do Ensino Fundamental II participam da manutenção como atividade escolar da disciplina de ciências.

Por fim, houve uma exposição das hortaliças cultivadas durante a Semana do Meio Ambiente, em que os alunos ficaram responsáveis por falar sobre a importância de uma agricultura mais sustentável e de hábitos alimentares mais saudáveis, permitindo a propagação dos conteúdos vistos durante a execução do projeto, despertando nos alunos das demais turmas uma visão mais crítica e o interesse de querer buscar mais conhecimento a respeito das temáticas abordadas.

\section{Conclusão}

Apesar dos resultados positivos, ainda há muito a ser feito no que diz respeito ao ensino da Educação Ambiental e nutricional no ambiente escolar, pois, o que decorre muitas vezes é a falta de continuidade em projetos semelhantes e considerados tão importantes. Vale ressaltar que a implantação de uma horta escolar, utilizada como ferramenta de ensino - como a do projeto desenvolvido - permite tanto para o professor, como para o aluno, um processo de ensino-aprendizagem mais interativo, dinâmico e lúdico, com diversas práticas pedagógicas no ensino de Ciências que fogem do cenário do cotidiano de uma sala de aula, permitindo o despertar do interesse do alunado através do novo. 


\section{Referências}

ARAÚJO, M.J.D.; SANTOS, M.R.; LIMEIRA, F.N.S. Educação alimentar e nutricional no currículo escolar. In: FERREIRA, G.R. (Org.). Educação: políticas, estrutura e organização 6. Paraná: 2019. v. 6.

ANSCHAU, J. R.; DOLIANITIS, B. M.; PAGLIARIN, G. C.; ZAPPE, J. A. et al. Projeto Horta Viva na Escola. Ciência e Natura, Santa Maria v.40, Edição Especial: II mostra de Projetos da UFSM - Campus Cachoeira do Sul, 2018, p. 148-155.

BARBIERI, J.C. Gestão ambiental empresarial: conceitos, modelos e instrumentos. 4. Ed. SP: Saraiva, 2016.

BATISTA, I.M. et al. Horta escolar: alimentação como fonte de prazer e sustentação. Universidade Estadual de Goiás. Goiás, s/n, p. 209 -218, 2013.

BIZZO, M.L.G.; LEDER, L. Educação nutricional nos parâmetros curriculares nacionais para o ensino fundamental. Revista de Nutrição, v.18, n.5, pp. 661667, 2005.

BOOG, M. C. F. Educação nutricional: passado, presente, futuro. Revista de nutrição, Campinas, v. 10, n. 1, p. 5-19, jan-jun., 1997.

BOOG, M. C. F. Educação nutricional em serviços públicos de saúde. Cadernos de saúde pública, Rio de Janeiro, v. 15, n. 2, p. 139-147, jan. 1999.

BRASIL. Política Nacional de Educação Ambiental. Lei 9.795/99. Brasília: Ministério do Meio Ambiente, 1999.

BRASIL. Política Nacional do Meio Ambiente. Lei n.ํ 6.938, de 31/08/81. Senado Federal. Disponível em: <http://www.cnpsa.embrapa.br/setorial/>. Acesso em 12 jan. 2022.

CANESQUI, A. M.; GARCIA, R. W. D. Uma introdução à reflexão sobre a abordagem sociocultural da alimentação. In: CANESQUI, A. M.; GARCIA, R. W. D. Antropologia e nutrição: um diálogo possível. Rio de Janeiro, RJ: Fiocruz, 2005. p. 9-19.

CASCUDO, L. C. Sociologia da alimentação. In: CASCUDO, L. C. História da alimentação no Brasil. São Paulo, SP: Ed. da Universidade de São Paulo, 1983. Vol.2. p.395-460.

CERVATO-MANCUSO, A.M.: VINCHA, K.R.R.; SANTIAGO, D.A. Educação alimentar e nutricional como prática de intervenção: reflexão e possibilidades de fortalecimento. Revista de saúde coletiva, Rio de Janeiro, v. 26, n. 1, p. 225-249, jan-mar., 2016.

DOBBERT, L. Y; SILVA, C.C; BOCCALETTO, E.M.A. Horta nas escolas: promoção da saúde e melhora na qualidade de vida. Disponível em $<$ http://www.fef.unicamp.br/departamentos/deafa/qvaf/livros/foruns interdiscipli nares saude/a fqv/livro afqv cap13.pdf>. Acesso: 05/06/2019. 
DIDONET, D.L.M.; SOUZA, J.P.; SOUZA, T.A. Práticas da Educação Ambiental: uma proposta de educação para o desenvolvimento sustentável. Rev. Eletrônica do Curso de Pedagogia do Campus, Jataí: UFG, v.11, n.1, 2015.

FERREIRA, V.G.M. et al. Educação Ambiental e o Ensino de Ciências: a horta escolar como instrumento facilitador no processo de ecoalfabetização. Congresso Latino-americano de Botânica. Congresso Nacional de Botânica. 54. Anais eletrônicos...Salvador - BA. 2014. Disponível em: $<$ http://www.botanica.org.br/trabalhos-cientificos/65CNBot/5083-ENB.pdf>.

Acesso em:10 nov. 2020.

GUENTHER, M. et al. Implementação de Composteiras e Hortas Orgânicas em Escolas: Sustentabilidade e Alimentação saudável. Revista Brasileira de Educação Ambiental, São Paulo, V. 15, No 7: 391-409, 2020.

IBGE - Instituto Brasileiro de Geografia e Estatística. Arapiraca (AL) | Cidades e Estados | IBGE. Disponível em <https://www.ibge.gov.br/cidades-eestados/al/arapiraca.html. Acesso em jan./2019>. Acesso em 20 jan 2021.

IRALA, C. H.; FERNANDEZ, P. M. Manual para Escolas. A Escola promovendo hábitos alimentares saudáveis. Horta. Brasília, 2001.

LEFF, E. Epistemologia ambiental. São Paulo: Cortez, 2001.

LIMA, A. R. F. Atividade interdisciplinar no ensino de ciências: entre o ideal e a realidade. 93f. Dissertação (Mestrado em Educação) - Universidade Federal de Pernambuco, Recife, 2008.

MEDEIROS, A. B. et al. A Importância da Educação Ambiental na escola nas séries iniciais. Revista Faculdade Montes Belos. Belo Horizonte, v. 04, n. 01, p. 22-26, 15 set 2011.

MENDES, F.C.P., LOPES, C.V.G., SALLES, J.O. Educação e meio ambiente. Curitiba: Fael, 2014.

MORGADO, F. S. A Horta Escolar na Educação Ambiental: experiência do projeto horta viva nas escolas municipais de Florianópolis, Revista Eletrônica de Extensão. 2008: (6) 1-10.

OLIVEIRA, S.I.; OLIVEIRA, K.S. Novas perspectivas em educação alimentar e nutricional. Psicologia USP, São Paulo, v. 19, n. 4, p. 495-504, out-dez. 2008.

OLIVEIRA, F. R.; PEREIRA, E. R.; ANTÔNIO PEREIRA JÚNIOR, A. Horta escolar, Educação Ambiental e a interdisciplinaridade. Revista Brasileira de Educação Ambiental, São Paulo, V. 13, No 2: 10-31, 2018.

OLIVEIRA, L.P.F.; SILVA, R.B. Educação Ambiental: Um estudo de caso a pratica da compreensão dos professores do ensino fundamental II. Revista brasileira de Educação Ambiental. São Paulo, V. 15. № 7: 86-105, 2020. 
PANTOJA, T. F. et al. A importância da horta escolar no processo ensino aprendizagem de botânica em uma escola de Macapá, AP. Anais do 64ํㅜㄴ Congresso Nacional de Botânica. Belo Horizonte, 2013.

PIPITONE, M. A.P. et al. A educação nutricional no programa de ciências para o ensino fundamental. Saúde em Revista, Piracicaba, v. 5, n. 9, p. 29-37, 2003.

RAMOS, M.; STEIN, L. M. Desenvolvimento do comportamento alimentar infantil. J. Pediatr., Rio de Janeiro, v.3, p. 229-37. 2000.

SANTOS, L.A.S. O fazer educação alimentar e nutricional: algumas contribuições para reflexão. Ciência \& Saúde Coletiva, Rio de Janeiro, v. 17, n. 2, p. 453-462, jan. 2012.

SANTOS, L. A. S. Educação alimentar e nutricional no contexto da promoção de práticas alimentares saudáveis. Revista de nutrição, Campinas, v. 18, n. 5, p. 681-692, set-out. 2005.

UNESCO. Década das Nações Unidas da Educação para um Desenvolvimento Sustentável, 2005-2014: documento final do esquema internacional de implementação. Brasília: UNESCO, 2005. 120p. 